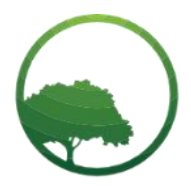

Research in Business \& Social Science

IJRBS VOL 10 NO 3 ISSN: 2147-4478

\title{
A systematic review of perceived value toward online review on s- commerce platform
}

\author{
(D) Nabhassorn Atchariyakarn ${ }^{(a) *}$ (D) Jing Zhang ${ }^{(b)}$ \\ (a) School of Management, University of Science and Technology, Wuhan, China. \\ (b) Professor,School of Management, University of Science and Technology, Wuhan, China
}

\author{
ARTICLE INFO \\ Article history: \\ Received 19 March 2021 \\ Received in rev. form 12 April 2021 \\ Accepted 18 April 2021 \\ Keywords: \\ Perceived Value; Online Review; e- \\ WoM; Social Commerce; Systematic \\ Review. \\ JEL Classification: \\ O15, P36
}

\begin{abstract}
A B S T R A C T
Online reviews play a significant role in supporting consumers to make purchase decisions across provided platforms. Many studies examine the characteristics of online reviews and their impacts, nevertheless, only a few studies examine the perceived value from online reviews. This study provides the integration view by utilizing the systematic approach to synthesize 36 academic papers out of 661 searched papers between January 1st, 2011, and December 22nd, 2019. The contribution of researchers in studying the perceived value is increasing significantly and continuously since 2018. There are two main types of online reviews regardless of online platforms: Expert-written reviews and customer-written reviews. Perceived values can be derived from online review and be transmitted to online review simultaneously upon the content of studies. The framing of questions for a review focus on five key questions and to illustrate by providing the mind mapping of perceived value to reveal components and relationship among them. The finding emphasizes the research contents of existing research and research allocation, analysis of techniques used, theories, methodologies used, implications in different industrial sectors to enhance the understanding of this relevant information, ambiguous meanings, and development of areas that lack attention in the past decade. Besides, the indication of studies could identify the importance of perceived values that has a greater impact on consumers in the pre-stage of purchase decision.
\end{abstract}

(C) 2021 by the authors. Licensee SSBFNET, Istanbul, Turkey. This article is an open access article distributed under the terms and conditions of the Creative Commons Attribution (CC BY) license (http://creativecommons.org/licenses/by/4.0/).

\section{Introduction}

With the rapidly development of marketing channels to enhance the sales volumes in online shopping, social commerce (s-commerce) is one of the largest channels in the present was introduced in 2005 by Yahoo and was known in the first academic article in 2006 (Han, 2018). S-commerce has the features for customers to generate the content such as reviews, ratings, recommendation lists, tags, and user profiles to encourage customers to share personal experiences and evaluations of purchased products. Customers are welcomed to share the information independently. S-commerce is not only an online community or platform for user generated content (UGC) but also provides the commercial value by attracting potential buyers from UGC and result in enhancing the profits to online vendors ( $\mathrm{Li}$, Chia-Ying, 2019). Customers' online reviews create the value of information and the experience that a customer has for a product or service while shopping through s-commerce platform. Consequently, customer online reviews have influence on sale volumes (Hajli, 2015). In order to indicate the

Plentiful studies have been conducted to understand the online review and perceived value but in different dimensions. There are few investigations on perceived value from online review. $\mathrm{Li}, 2013$; reports review helpfulness and usefulness are difficult to understand from earlier studies even its connection has examined. Since 2011 the published studies on online review increased, but little attempt has been made to incorporate the findings of former surveys and assess the current state of the research in this field. In this study, it is conducting a systematic review of perceived values from online reviews in social commerce; to explore the term perceived values by collecting, reviewing, and synthesizing studies that related to s-commerce published from 2011 to 2019 . A systematic review is a

* Corresponding author. ORCID ID: 0000-0003-4407-4274

(C) 2021by the authors. Hosting by SSBFNET. Peer review under responsibility of Center for Strategic Studies in Business and Finance. https://doi.org/10.20525/ijrbs.v10i3.1127 
research method and process for identifying, extracting, and grouping relevant research to enhance the understanding of focal phenomenon, as well as for providing readers the insights on conflicting findings that useful for future research (Palmatier,2018), (Fang, 2016). The significance of this study aims to retrieve the meaningful from perceived values and discuss the limitations of prior research as well as opportunities for future research.

Five key questions are listed as the tremendous domains to provide a clear view and explore the perceived value concept systematically in this study.

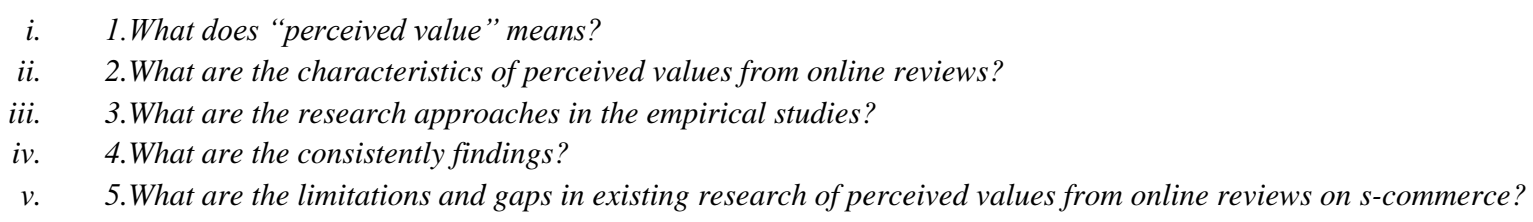

The outline of this study is comprised of a comprehensive understanding of perceived value from online review using the collected data from 36 academic papers out of 661 searched academic papers followed by data synthesis. Finally, bring up the development areas to be useful for marketers, enterprises, customers, and researchers. Besides the study could lead to implication toward the study of perceived value toward online reviews on social commerce. The implication could be beneficial to boost marketing and sales resulting from the more understanding customer perceived value on social commerce platform.

This study starts by the theoretical foundation for further systematic reviewing which identify online review and perceived value meaning synthesis, followed by systematic review approach with the illustration of study model from data extraction, finding and results conclusion and implication for future study.

\section{Theoretical Foundations}

With the incremental growth of online reviews in s-commerce, the value of online review is defined by using two components. One component is review itself and the other component is the reviewer. Both of these components influence the value of online review (Fang, 2016). Recently, (Busalim, 2019) provides the research framework of factor influence customer engagement in s-commerce by presenting perceived value as one of motivation factors and acts as antecedent in generating online review. In another study (Hong, 2017), online reviews decrease the uncertainty and risk of online shopping. In order to explicitly understand perceived value and online review, the literature review of these terms is conducted.

\section{Online Review}

Online review by customers have more significant in term of supporting products or service information than online re-view by advertisers or product experts (Huang, 2015). The result of research shows that other traveler's reviews are more likely to contain enjoyable, reliable, and up-to-date information (Gretzel, 2008). Online reviews empower consumers to gain information with credibility and high trustworthiness. Many researchers in marketing and information systems aware the importance of online reviews by estimating the effect of online reviews on three main aspects: consumer behaviors, product sales, and user's perception of information (Park, 2015). Consumers are able to choose and adopt the information in order to make decision based upon two different aspects of the information process: enjoyment and usefulness. Enjoyment is an intrinsic motivation lead to customer behavior without apparent reason. Usefulness is an extrinsic motivation by considering the information as instrumental value (Moon, 2001).

\section{Perceived value}

S-commerce permits consumers to receive information with-out limitation at low costs, but information may be overload-ed and consume time to decide helpfulness of information. The concepts of perceived value have been studied in different aspects. Empirical results from (Li \& Zili, 2018) shows that temporal cues of online reviews affect review usefulness but not re-view enjoyment; explanatory cues have an important effect on both review usefulness and review enjoyment; sensory cues show much stronger effects on review enjoyment than on review usefulness. (Handi, 2018) examined the effect of electronic word of mouth and perceived value on purchase decisions by referring perceived value, as customers perceive the sacrifice and expenditure given in accordance with benefits they expect. In addition, perceived value is under the evaluation of customer about service or a product that is offered and considers the benefits received and cost incurred. The conclusion of perceived value is a customer's assessment in evaluation process before purchasing a product or service. However, the implication of perceived value is existed, as the conceptual framework of the earlier research has no direct impact from electronic word of mouth to perceived value.

\section{Systematic Review Approach}

This study uses a systematic review approach for gaining deeply knowledge, facilitate theory development and integrate the finding for further studies are illustrated by the below table 1: data extraction method of primary studies to identify further illustration. 
Table 1: Data extraction of primary studies

\begin{tabular}{ll}
\hline Extracted data & Description \\
\hline Study ID & Unique ID for the primary study \\
Authors & Name of all the authors \\
Study Title & The name of the paper which appears as the title \\
Publication Date & The year of publishing the paper which may be from different sources i.e., books, conferences, \\
& journals, etc. \\
Source & Name of journals, books, conference papers, dissertations \\
Data Collection & Volume of collected data in the study \\
Data Collection Method & Method of data collection i.e., online survey, systematic review, case study, etc. \\
Industry & Business sector or Industry type \\
Analysis Technique & Mathematic technique \\
Theory & The adopted theories in the paper i.e., Technology acceptance Model (TAM), Stimuli-Organism- \\
& Response Model(S-O-R), etc. \\
Research Method & Technique in analysis i.e., quantitative, systematic review, meta-analysis, etc. \\
Findings & The result from analysis or studied part \\
Limitation & Limitation of the study for future research \\
Review Protocol &
\end{tabular}

An overview and guidelines of a research methodology has been studied and described in the academic research (Snyder, 2019). Figure1 illustrates the review protocol in this research.

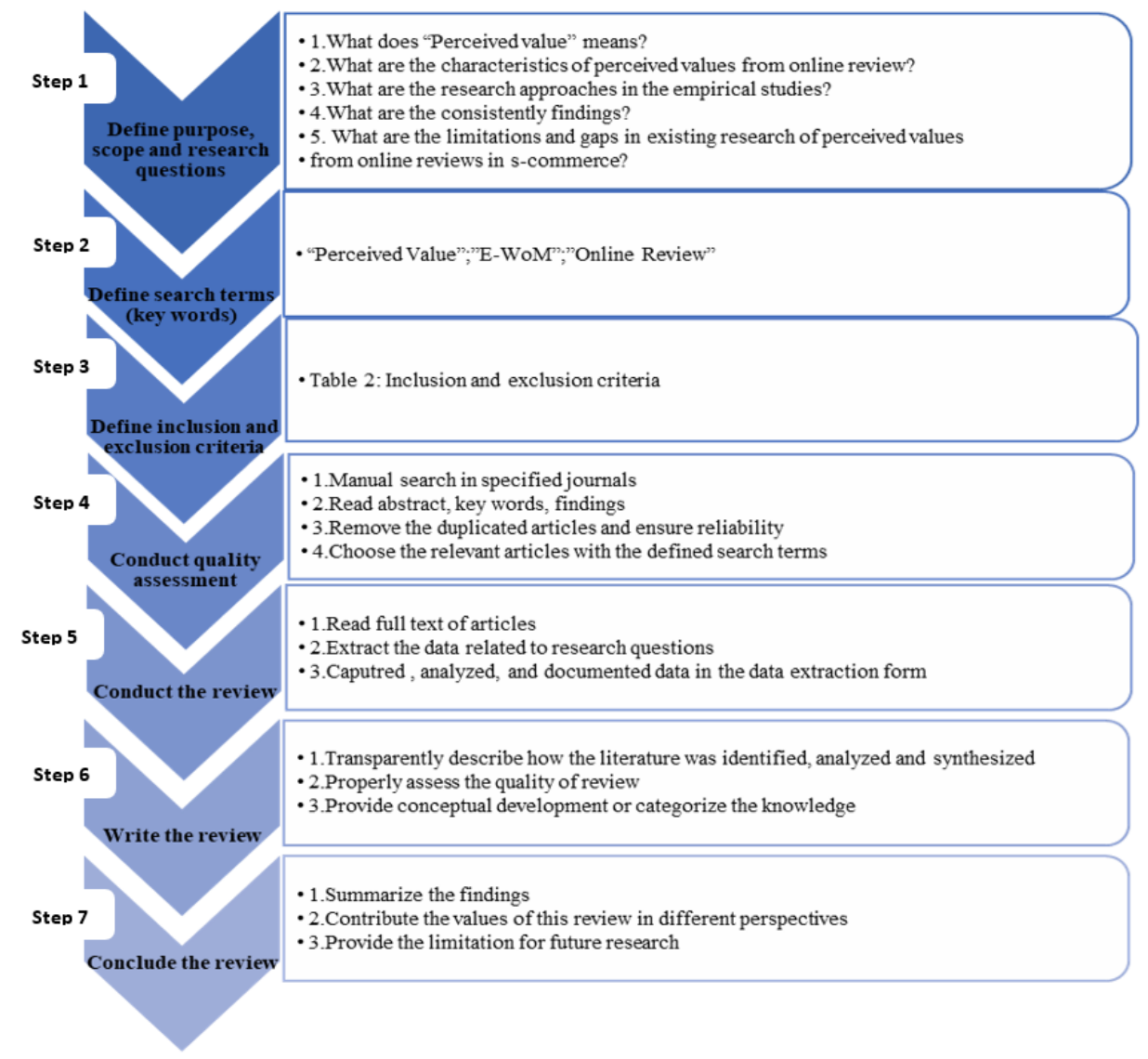

Figure 1: Review Protocol

\section{Inclusion and exclusion criteria}

Importantly, a systematic review must decide the inclusion and exclusion criteria in selecting search terms and appropriate database. Commonly used criteria including year of publication, language of article, and journal. Without inclusion and exclusion criteria, the quality of research may be impacted due to lacking sufficient data to conclude the gaps in literatures (Snyder, 2019). 
Table 2: Inclusion and exclusion criteria

\begin{tabular}{lll}
\hline Criteria & Inclusion & Exclusion \\
\hline Published year & $2010-2018$ & Not in inclusion list \\
Full-text & Completed studies & Uncompleted studies \\
Language & English & Not in English \\
Domain & S-commerce & Out of inclusion list \\
Journal & ScienceDirect, & Out of inclusion list \\
& Scopus, Springer, IEEE Explorer, & \\
\multicolumn{2}{l}{ Search and Selection Process } & ACM Digital Library
\end{tabular}

Applying inclusion and exclusion criteria in table 2, the automatic search was used by identified search terms in the research questions to search in the specific journals. The identified search terms are: "perceived value" and "online review"; "perceived value" and "eWOM". Using the search terms, the result of initial search was 661 articles from the inclusive sources and defined published year. After re-moving the duplicated articles, the next process is to scan the title, abstract, introduction and findings.

\section{Quality assessment process}

Enriching the confidence in the reliability and credibility of the selected studies, quality assessment process is included in this study by applying the questions from prior study (Busalim, 2016). The topic of selected studies must relate to perceived value from online review with explanation the research methodology and data collection. Analysis technique must be explicitly presented in the selected studies.

\section{Data extraction and synthesis}

A data extraction form is designed to record the data from reading a full-text review of 36 articles. The following data were extracted: article title, journal name, published year, study field, theory, analysis approach, number of samples, findings, and limitation for future study by using Microsoft Excel as a tool. The distribution of the studies based on journal is shown in Figure 2:

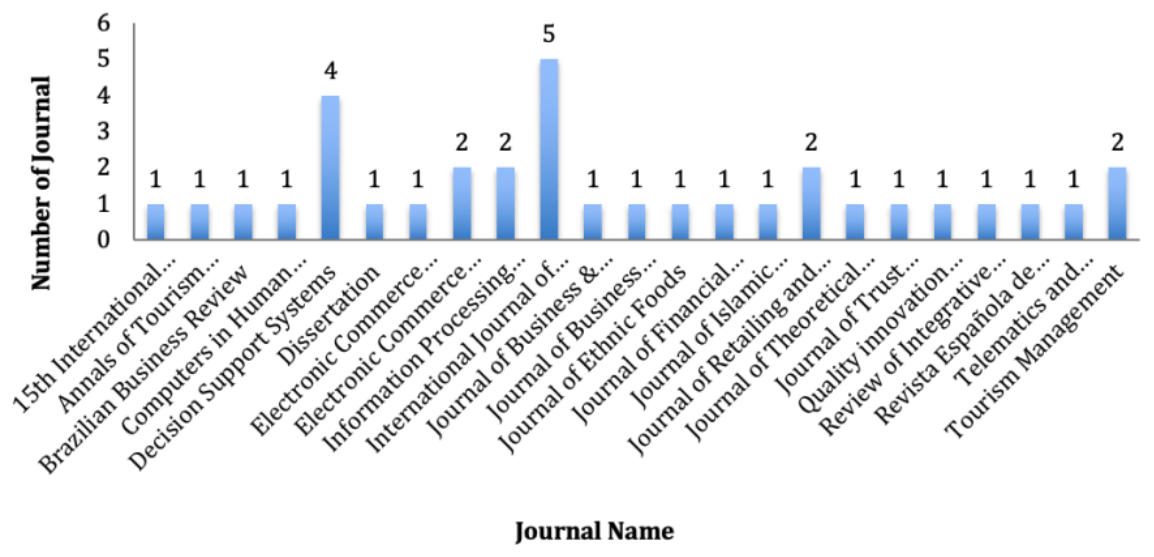

Figure 2: Distribution of studies based on journal

The distribution of the studies based on publish year from 2011 to 2019 is shown in Figure 3: The industry fields of studies are shown in Figure 4. The majority of studies are mixed across industries followed by travel and food.

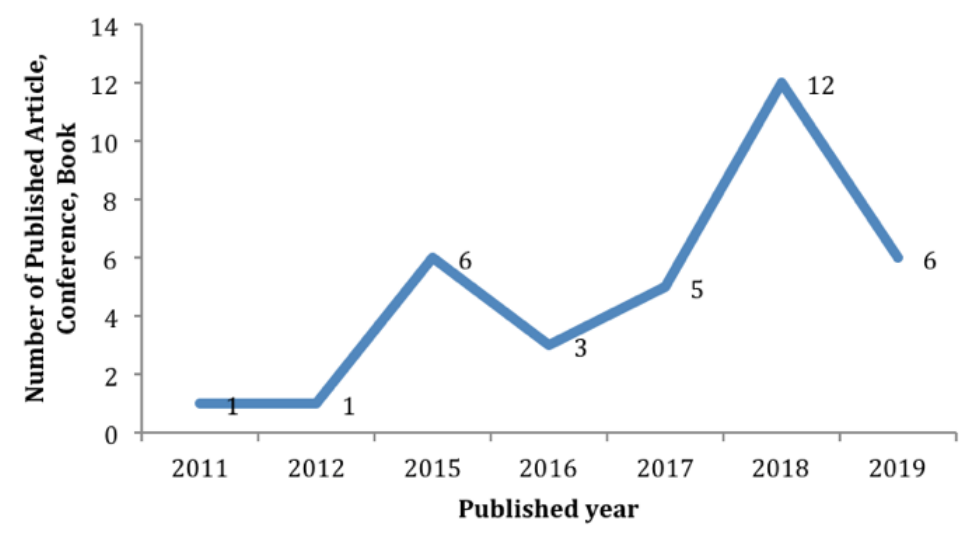

Figure 3: Distribution of studies based on published year 


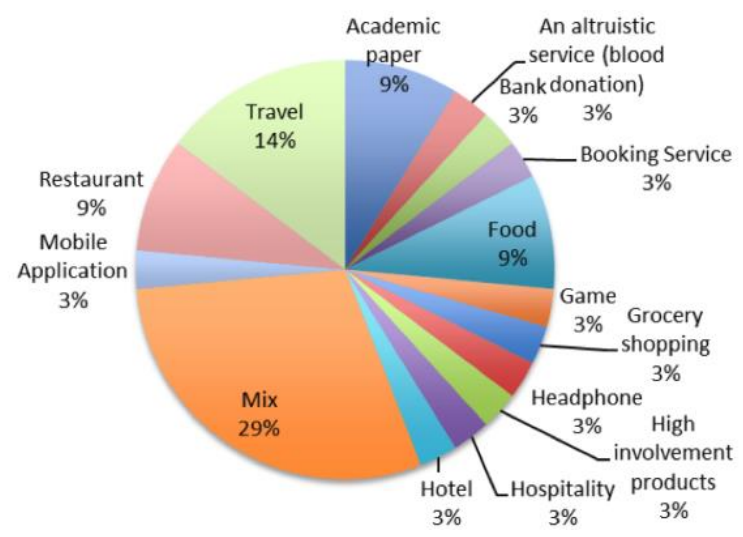

Figure 4: Distribution of studies based on industry fields

The period of time selected in 36 studies is 2011 to 2019. In the first year, the study is the dissertation of PhD. student to examine the perceived usefulness and economic impact from online review by using the samples from Amazon.com. In 2015, the number of studies increases to 6 , then become to 12 in 2018 .

\section{Findings}

A mind map in figure 5 shows perceived value in the aspects of theory, analysis techniques, customer views, customer engagement, sentiment, information, and moderate factors for reporting the characteristics and findings from 36 studies. Quantitative method has the higher ratio than qualitative method in these studies. A systematic and data mining is another research method use in a small group of studies. The limitations of all 36 studies are the online platforms, limited regions, and samples. Table 3 conclude finding of several research and perceived value information

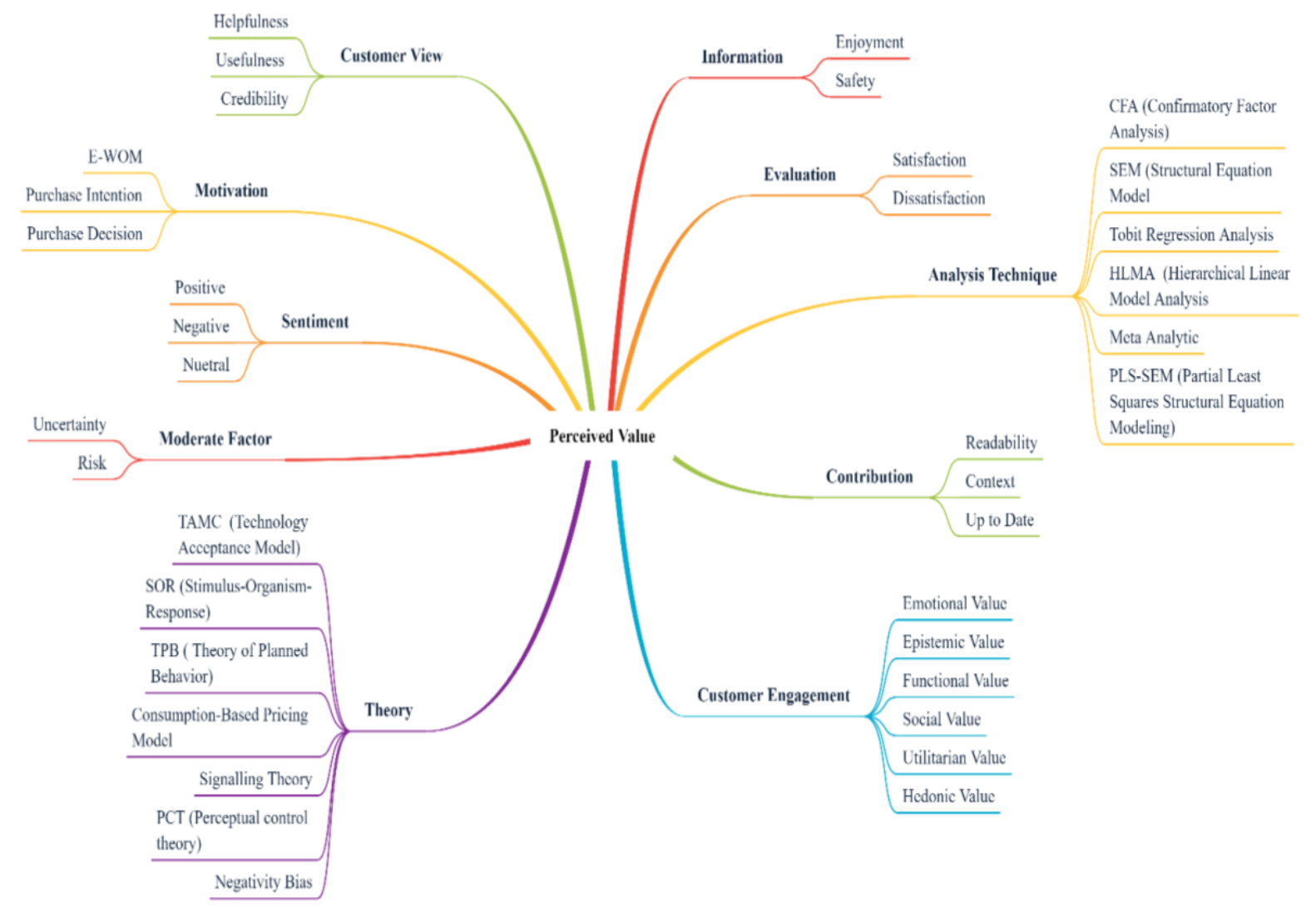

Figure 5: Mind map of perceived value's attributes 
Table 3: Perceived value's attributes

\begin{tabular}{|c|c|c|}
\hline Title & Author & Perceived value \\
\hline $\begin{array}{l}\text { Subjective perception patterns of online reviews: A comparison of utilitarian } \\
\text { and hedonic values }\end{array}$ & (Ham, 2019) & Utilitarian and hedonic values \\
\hline $\begin{array}{l}\text { Examining the relationship between specific negative emotions and the } \\
\text { perceived helpfulness of online reviews }\end{array}$ & (Ren, 2018) & Emotion value \\
\hline What makes a useful online review? Implication for travel product websites & (Liu, 2015) & $\begin{array}{l}\text { Emotion value, } \\
\text { Usefulness }\end{array}$ \\
\hline $\begin{array}{l}\text { Analysis of the perceived value of online tourism reviews: Influence of } \\
\text { readability and reviewer characteristics }\end{array}$ & (Fang, 2016) & Readability \\
\hline $\begin{array}{l}\text { Explaining and predicting online review helpfulness: The role of content and } \\
\text { reviewer-related signals, }\end{array}$ & (Siering, 2018) & Helpfulness \\
\hline Online review helpfulness: Impact of reviewer profile image & (Karimi, 2017) & Helpfulness \\
\hline A study of factors that contribute to online review helpfulness & (Huang, 2015) & Helpfulness \\
\hline $\begin{array}{l}\text { Understanding the determinants of online review helpfulness: A meta-analytic } \\
\text { investigation }\end{array}$ & (Hong, 2017) & Helpfulness \\
\hline $\begin{array}{l}\text { Which online reviews do consumers find most helpful? A multi-method T } \\
\text { investigation }\end{array}$ & (Eslami, 2018) & Helpfulness \\
\hline What makes a helpful online review? A meta-analysis of review characteristics & (Wang, 2019) & Helpfulness \\
\hline $\begin{array}{l}\text { Making restaurant reviews useful and/or enjoyable? The impacts of temporal, } \\
\text { explanatory, and sensory cues }\end{array}$ & $(\mathrm{Li}, 2018)$ & Usefulness \\
\hline Asymmetric effects of online consumer reviews & (Park, 2015) & Usefulness, Enjoyment \\
\hline $\begin{array}{l}\text { Perceived influence on behavior of user-generated content on social network } \\
\text { sites: An empirical application in the hotel sector }\end{array}$ & (Herrero, 2015) & Information \\
\hline $\begin{array}{l}\text { How buyers perceive the credibility of advisors in online marketplace: review } \\
\text { balance, review count and misattribution }\end{array}$ & (Wu, 2015) & $\begin{array}{l}\text { Trust } \\
\text { (Transmitted Value) }\end{array}$ \\
\hline $\begin{array}{l}\text { The Effect of E-WOM and Perceived Value on the Purchase Decision of } \\
\text { Foods by Using the Go-Food Application as Mediated by Trust }\end{array}$ & (Handi, 2018) & $\begin{array}{l}\text { Trust } \\
\text { (Transmitted Value) }\end{array}$ \\
\hline $\begin{array}{l}\text { Empirical Research on the Impact of Internet Word of Mouth on Customer } \\
\text { Citizenship Behavior, }\end{array}$ & (Luo, 2018) & Price \\
\hline $\begin{array}{l}\text { Examining impacts of negative reviews and purchase goals on consumer } \\
\text { purchase decision }\end{array}$ & (Weisstein, 2017) & Sentimental, quality \\
\hline $\begin{array}{l}\text { Perceived Value, e-Word-of-Mouth, Traditional Word- of-Mouth, and } \\
\text { Perceived Quality to Destination Image of Vacation Tourists }\end{array}$ & Christin, 2018) & Quality (Transmitted Value) \\
\hline
\end{tabular}

\section{Conclusions}

After data synthesis process, 36 selected studies provide an empirical view of perceived value from online reviews, indicating that consumers seek for more information before buying or making a purchase decision from online review when they are in the circumstance of uncertainty on the particular products or services. Helpfulness, usefulness, safety, enjoyment, satisfaction, hedonic $\&$ utilitarian, emotional, social, functional, epistemic values are the perceived values from online review either direct or indirect relationship. The industry fields could be one of moderator to analyze in the future research. Numerous data of online review in scommerce platforms should be considered to explore the negative perceived values in the future research for enhancing the knowledge of marketers, enterprises, and researchers to eliminate the possible sources in generating the negative perceive value.

An important managerial implication is the deriving and transmitting perceived values. Both of deriving and transmitting the perceived values has greater impact to consumers in pre-stage of purchase decision. Therefore, the study of insight customer perceived value is crucial to boost up sales and preventing negative perceived values should be identified and study further.

\section{References}

Busalim, A. H., \& Hussin, A. R. C. (2016). Understanding social commerce: A systematic literature review and directions for further research. International Journal of Information Management, 36(6), 1075-1088. https://doi.org/10.1016/ j.ijinfomgt. 2016.06.005

Busalim, A. H., Che Hussin, A. R., \& Iahad, N. A. (2019). Factors Influencing Customer Engagement in Social Commerce Websites: A Systematic Literature Review. Journal of theoretical and applied electronic commerce research, 14(2), 0-0. http://dx.doi.org/10.4067/S0718-18762019000200102

Christin Susilowati, D.S., Perceived Value, eWord-of-Mouth, Traditional Word- of-Mouth, and Perceived Quality to Destination Image of Vacation Tourists. Review of Integrative Business and Economics Research, 2018. 7(1): p. 312-321

Eslami, Pouyan \& Ghasemaghaei, Maryam \& Hassanein, Khaled. (2018). Which online reviews' do consumers find most helpful: A multimethod investigation? Decision Support Systems. 113. https://doi.org/10.1016/j.dss.2018.06.012

Fang, Bin \& Ye, Qiang \& Kucukusta, Deniz \& Law, Rob, 2016. "Analysis of the perceived value of online tourism reviews: Influence of readability and reviewer characteristics," Tourism Management, Elsevier, vol. 52(C), pages 498-506. https://doi.org/10.1016/j.tourman.2015.07.018

Gretzel, Ulrike \& Yoo, Kyung-Hyan. (2008). Use and Impact of Online Travel Reviews. Information and Communication Technologies in Tourism 2008. 35-46. https://doi.org/10.1007/978-3-211-77280-5_4 
Hajli, N. (2015). Social commerce constructs and consumer's intention to buy. International Journal of Information Management, 35(2), 183-191. https://doi.org/10.1016/j.ijinfomgt.2014.12.005

Ham, J., Lee, K., Kim, T., \& Koo, C. (2019). Subjective perception patterns of online reviews: A comparison of utilitarian and hedonic values. Information Processing \& Management, 56(4), 1439-1456. https://doi.org/10.1016/j.ipm.2019.03.011

Handi, Handi \& Hendratono, Tonny \& Purwanto, Edi \& Ihalauw, John. (2018). The Effect of E-WOM and Perceived Value on the Purchase Decision of Foods by Using the Go-Food Application as Mediated by Trust. Quality Innovation Prosperity. 22. 112. https://doi.org/10.12776/qip.v22i2.1062

Han, Hui \& Xu, Hongyi \& Chen, HongQuan. (2018). Social commerce: A systematic review and data synthesis. Electronic Commerce Research and Applications. https://doi.org/10.1016/j.elerap.2018.05.005

Herrero Crespo, Á., San Martín Gutiérrez, H., \& Hernández Mogollón, J. M. (2015). Perceived influence on behavior of usergenerated content on social network sites: An empirical application in the hotel sector. Revista Española de Investigación de Marketing ESIC, 19(1), 12-23. https://doi.org/10.1016/j.reimke.20

Hong, H., Xu, D., Wang, G. A., \& Fan, W. (2017). Understanding the determinants of online review helpfulness: A meta-analytic investigation. Decision Support Systems, 102, 1-11. https://doi.org/10.1016/j.dss.2017.06.007

Huang, Albert \& Chen, Kuanchin \& Yen, David \& Tran, Trang. (2015). A study of factors that contribute to online review helpfulness. Computers in Human Behavior. 48. 17-27. https://doi.org/10.1016/j.chb.2015.01.010.

Karimi, S., \& Wang, F. (2017). Online review helpfulness: Impact of reviewer profile image. Decision Support Systems, 96, 39-48. https://doi.org/10.1016/j.dss.2017.02.001

Li, Chia-Ying, 2019. "How social commerce constructs influence customers' social shopping intention? An empirical study of a social commerce website," Technological Forecasting and Social Change, Elsevier, vol. 144(C), pages 282-294. https://doi.org/10.1016/j.techfore.2017.11.026

Li, Hengyun \& Wang, Renee \& Meng, Fang \& Zhang, Zili. (2018). Making Restaurant Reviews Useful and/or Enjoyable? The Impacts of Temporal, Explanatory, and Sensory Cues. International Journal of Hospitality Management. https://doi.org/10.

1016/j.ijhm.2018.11.002

Li, M., Huang, L., Tan, C.-H., \& Wei, K.-K. (2013). Helpfulness of Online Product Reviews as Seen by Consumers: Source and Content Features. International Journal of Electronic Commerce, 17(4), 101-136. https://doi.org/10.2753/JEC1086441570404

Liu, Zhiwei \& Park, Sangwon. (2015). What makes a useful online review? Implication for travel product websites. Tourism Management. 47. 140-151. https://doi.org/10.10 16/j.tourman.2014.09.020

Luo, H., Huang, X., Fan, Y., Su, F., Huang, W., Feng, W., \& Chen, Y. (2018). Empirical Research on the Impact of Internet Word of Mouth on Customer Citizenship Behavior. https://doi.org/10.1109/ICSSSM.2018.8465037

Moon, J.-W., \& Kim, Y.-G. (2001). Extending the TAM for a World-Wide-Web context. Information \& Management, 38(4), $217-$ 230. https://doi.org/10.1016/S0378-7206(00)00061-6

Palmatier, R. W., Houston, M. B., \& Hulland, J. (2018). Review articles: purpose, process, and structure. Journal of the Academy of Marketing Science, 46(1), 1-5. https://doi.org/10.1007/s11747-017-0563-4

Park, Sangwon \& Nicolau, Juan. (2015). Asymmetric effects of online consumer reviews. Annals of Tourism Research. 50. 67-83. https://doi.org/10.1016/j.annals.2014.10.007

Ren, Gang \& Hong, Taeho. (2019). Examining the relationship between specific negative emotions and the perceived helpfulness of online reviews. Information Processing \& Management. 56. 1425-1438. https://doi.org/10.1016/j.ipm.2018.04.003

Siering, Michael \& Muntermann, Jan \& Rajagopalan, Balaji. (2018). Explaining and predicting online review helpfulness: The role of content and reviewer-related signals. Decision Support Systems. 108. https://doi.org/10.1016/j.dss.2018.01.004

Snyder, H. (2019). Literature review as a research methodology: An overview and guidelines. Journal of Business Research, 104, 333-339. https://doi.org/10.1016/j.jbusres.2019.07.039

Wang, Yani \& Wang, Jun \& Yao, Tang. (2019). What makes a helpful online review? A meta-analysis of review characteristics. Electronic Commerce Research. 19. https://doi.org/10.1007/s10660-018-9310-2.

Weisstein, F., Song, L., Andersen, P., \& Zhu, Y. (2017). Examining Impacts of Negative Reviews and Purchase Goals on Consumer Purchase Decision. Journal of Retailing and Consumer Services, 39, 201-207. https://doi.org/10.1016/j.jretconser

.2017.08.015

Wu, K., Noorian, Z., Vassileva, J., \& Adaji, I. (2015). How buyers perceive the credibility of advisors in online marketplace: review balance, review count and misattribution. Journal of Trust Management, 2. https://doi.org/10.1186/s40493-015-0013-5

Publisher's Note: SSBFNET stays neutral with regard to jurisdictional claims in published maps and institutional affiliations.

\section{(c) (1)}

(C) 2021 by the authors. Licensee SSBFNET, Istanbul, Turkey. This article is an open access article distributed under the terms and conditions of the Creative Commons Attribution (CC BY) license (http://creativecommons.org/licenses/by/4.0/).

International Journal of Research in Business and Social Science (2147-4478) by SSBFNET is licensed under a Creative Commons Attribution 4.0 International License. 